\title{
Association of Aortic Pulse Wave Velocity with the Severity of Coronary Artery Disease in Patients with Acute ST Elevation Myocardial Infarction
}

\author{
MA Razzaque, AAS Majumder, MT Rahman, AKMM Islam, M Ullah, MA Rahman, AR Khan, SMA Romel \\ Department of cardiology,National Institute of Cardiovascular Disease,Dhaka,Bangladesh
}

\begin{abstract}
Keywords:
Pulse wave

velocity $(P W V)$,

STEMI,

Coronary artery

disease $(C A D)$.
\end{abstract}

\begin{abstract}
Background: Arterial stiffness assessed noninvasively with aortic pulse wave velocity $(P W V)$ has been associated with atherosclerosis in the coronary arteries and also cardiovascular mortality. The aim of this study was to evaluate the association between aortic PWV and severity of coronary artery disease (CAD) in patients with acute ST elevation myocardial infarction (STEMI).

Methods: This cross sectional analytical study was conducted over 200 acute STEMI patients who were purposively selected and agreed to do coronary angiogram during index hospital admission. Assessment of aortic PWV was performed noninvasively with the commercially available SphygmoCor system using applanation tonometry with high fidelity micromanometer on the day before angiogram. Study subjects were subdivided into two groups on the basis of PWV. In group I: aortic PWV was d" $10 \mathrm{~m} / \mathrm{sec}$ and in group II: aortic PWV was $>10 \mathrm{~m} / \mathrm{sec}$. One hundred patients were included in each group. Angiographic severity of CAD was assessed by vessel score, Friesinger score and Leaman score.

Results: Vessel score 0 and 1 were significantly higher in group $I(p<0.05)$ where vessel score 2 and 3 were significantly higher in group II $(p<0.05)$. The mean PWV in the group with normal angiographic result was $8.10 \pm 2.9 \mathrm{~m} / \mathrm{sec}$, and in patients with single vessel disease it was $11.65 \pm 3.46 \mathrm{~m} / \mathrm{sec}$. In those with double and triple vessel disease the mean value of $P W V$ was found $13.85 \pm 3.80$ and $15.70 \pm 4.66 \mathrm{~m} / \mathrm{sec}$ respectively. The mean value of $P W V$ increased in proportion with the number of vessel involved by $C A D$ and the differences were statistically significant $(p=0.001)$. The mean value of $P W V$ was observed $8.5 \pm 2.3$ and $12.5 \pm 3.7 \mathrm{~m} / \mathrm{sec}$ in insignificant and significant CAD respectively using Friesinger score and the difference was statistically significant $(p<0.05)$. There was statistically significant positive linear relation between the values of PWV and vessel score $(r=.62, p=0.01)$, Friesinger score $(r=.64, p=0.01)$ and Leaman score $(r=.45$, $p=0.01$ ).
\end{abstract}

Conclusion: Aortic PWV is associated with the extent and severity of CAD. This noninvasive, cheap, radiation free method may be considered as risk stratification tool beyond other investigations.

(Cardiovasc. j. 2014; 6(2): 116-121)

\section{Introduction:}

Endothelium modulates arterial stiffness, which precedes overt atherosclerosis and is an independent predictor of cardiovascular events. ${ }^{1}$ Increased arterial stiffness has been associated with increased risk of MI, stroke, congestive heart failure and overall morality. ${ }^{2}$ Increased arterial stiffness correlates with coronary risk factors as well as measures of arterial stiffness correlate with the presence of angiographic CAD. ${ }^{3}$ Noninvasive assessment of arterial stiffness may serve as a useful adjunct to the cardiovascular risk stratification and risk management. ${ }^{4}$
Among the different noninvasive methods used to assess arterial stiffness the carotid femoral pulse wave velocity (PWV) has emerged as a gold standard due to its accuracy, reproducibility, relative easy measurement, and low costs. ${ }^{5}$ Applanation tonometry may be used to derive central arterial pressure waveforms and several indices of arterial stiffness, when electrocardiography (ECG)-gated, arterial waveforms obtained at different sites can be used to calculate the velocity of arterial pulse wave. ${ }^{6} \mathrm{PWV}$ is not only a useful marker to predict the severity of $\mathrm{CAD}^{7}$ but also a predictor of prognosis of patients with acute coronary

Address of Correspondence : Dr. Muhammed Aminur Razzaque, Department of Cardiology, National Institute of Cardiovascular Diseases, Dhaka, Bangladesh. E-mail: aminurrazzaque@gmail.com. 
syndrome(ACS). ${ }^{8}$ Studies related to the aortic PWV and severity of coronary artery disease in acute myocardial infarction population so far have predominantly been carried out in the developed countries. Though among the different invasive and noninvasive methods coronary angiography is the gold standard for the detection of severity of CAD, this noninvasive tool for the prediction of severity of CAD in acute STEMI patients can be used in the management of this subset of acute coronary syndrome patients in general. So the present study was planned and carried out.

\section{Materials and methods:}

This cross sectional analytical study was conducted in the national institute of cardiovascular disease, Dhaka from July 2011 to October 2012. Patents were purposively selected from those who were admitted in NICVD with acute STEMI myocardial infarction and agreed to do coronary angiography during index hospital admission. Total 200 patients were included in the study. Assessment of PWV was performed noninvasively with the commercially available SphygmoCor system (The SphygmoCor Vx pulse wave Analysis system Model SCOR-Mx_DCN: 100521 P/N:1-00418, Rev:9.0/0-0m, SphygmoCor Software Version: 8, AtCor Medical Private Ltd) using applanation tonometry with a high-fidelity micromanometer (Millar Instruments). Patients with valvular heart disease, congenital heart disease and cardiomyopathy, suspected myocarditis or pericarditis, major non cardiovascular disorder such as severe renal impairment, uncontrolled hypertension (systolic blood pressure $>160 \mathrm{mmHg}$ ), prior PCI or CABG, patients with left ventricular systolic dysfunction ( ejection fraction $<40 \%$ ), patients known to have significant peripheral arterial disease i.e, atherosclerosis, coarctation of aorta, aortic aneurysm, aortic dissection were excluded from the study. Study protocol was approved by the Ethical Review Committee of NICVD.

\section{Noninvasive assessment of pulse wave velocity:}

PWV was assessed noninvasively using the SphygmoCor ${ }^{\circledR}$ system. ECG-gated carotid and femoral waveforms were recorded using applanation tonometry. Carotid-femoral path length was measured as the difference between the surface distances joining (1) the suprasternal notch, the umbilicus and the femoral pulse and (2) the suprasternal notch and the carotid pulse. Carotid-femoral transit time was estimated in 810 sequential femoral and carotid waveforms as the average time difference between the onset of the femoral and carotid waveforms. The foot of the pulse wave was identified using the intersecting tangent method. PWV was calculated as the carotid-femoral path length divided by the carotidfemoral transit time. This is an established, noninvasive and reproducible method to determine arterial stiffness and no adjustments are required for transit time and path length. ${ }^{9}$

All pulse wave velocity measurements were taken in a quiet, temperature-controlled room $\left(22 \pm 11^{\circ} \mathrm{C}\right)$ after a brief period (at least 5 minutes) of rest, most often on the day before cardiac catheterization by a doctor not involved in performance or interpretation of the angiograms.

\section{Assessment of angiographic pattern and severity of CAD:}

Coronary angiography was done during index hospital admission. Interpretation of coronary angiogram was done by visual estimation by two cardiologists to assess the severity of coronary artery disease. Severity of coronary stenosis was graded according to the number of major epicardial vessel with significant stenosis (vessel score), Friesinger score and Leaman score.

\section{A. Vessel score: ${ }^{10}$}

This is the number of vessels with a significant stenosis (for left main coronary artery $50 \%$ or greater and for others $70 \%$ or greater reduction in luminal diameter). ${ }^{11}$ Score ranged from 0 to 3 , depending on the number of vessel involved. Left main coronary artery was scored as single vessel disease. ${ }^{12}$

Score $0=$ no vessel involvement.

Score $1=$ single vessel involvement.

Score $2=$ double vessel involvement.

Score $3=$ triple vessel involvement.

\section{B. Friesinger score: 10}

The Friesinger index is a score ranges from 0 to 15. Each of the three main coronary arteries was scored separately from 0 to 5 .

Score 0 : No arteriographic abnormality

Score 1: Trivial irregularities (lesion from $1-29 \%)$ 
Score 2: Localized 30-68\% luminal narrowing

Score 3: Multiple 30-68\% luminal narrowing of same vessel;

Score $4: 69-100 \%$ luminal narrowing without $100 \%$ occlusion of proximal segments

Score 5: Total obstruction of a proximal segment of a vessel.

\section{Statistical Methods:}

Data were collected by using a pre designed data sheet. Data were presented as frequency and percentage for categorical variables and as mean with standard deviation for quantitative variables. Categorical variables were analyzed by chi-square test. Quantitative variables were analyzed by t-test or ANOVA. Correlations between pulse wave velocity and angiographic severity was measured by Pearson's and Spearman - s correlation test. To identify independent effects of risk factors on coronary artery disease multivariate regression analysis was done. $\mathrm{P}$ value less than 0.05 was considered as significant. Statistical analyses were performed with SPSS, version 16.0 (SPSS Inc).

\section{Results:}

This study was done with an aim to find out the association between the aortic pulse wave velocity and the angiographic severity of coronary artery disease in patients with acute ST elevation myocardial infarction. On the basis of PWV, study subjects were categorized into two groups: 100 patients of acute STEMI with normal pulse wave velocity (d" $10 \mathrm{~m} / \mathrm{sec}$ ) were considered as group I and 100 patients of acute STEMI with increased pulse wave velocity (> $10 \mathrm{~m} / \mathrm{sec}$ ) were considered as group II.

Table-I

Distribution of Risk factors of the study population $(n=200)$

\begin{tabular}{|c|c|c|c|c|c|}
\hline \multirow[t]{2}{*}{ Risk Factors } & \multicolumn{2}{|c|}{$\begin{array}{l}\text { Group I } \\
(\mathrm{n}=50)\end{array}$} & \multicolumn{2}{|c|}{$\begin{array}{l}\text { Group II } \\
(\mathrm{n}=50)\end{array}$} & \multirow[t]{2}{*}{$\mathrm{P}$ value } \\
\hline & Number & $\%$ & Number & $\%$ & \\
\hline Smoking & 52 & 52.0 & 67 & 67.0 & $0.03^{\mathrm{s}}$ \\
\hline Hypertension & 42 & 42.0 & 54 & 54.0 & $0.09^{\text {ns }}$ \\
\hline Diabetes mellitus & 49 & 49.0 & 59 & 59.0 & $0.15^{\mathrm{ns}}$ \\
\hline Dyslipidemia & 38 & 38.0 & 49 & 49.0 & $0.12^{\mathrm{ns}}$ \\
\hline $\begin{array}{l}\text { Family } \mathrm{H} / \mathrm{O} \\
\text { premature } \mathrm{CAD}\end{array}$ & 18 & 18.0 & 30 & 30.0 & $0.04^{\mathrm{s}}$ \\
\hline
\end{tabular}

Table I shows that smoking and family history of premature $\mathrm{CAD}$ were significantly higher in Group II $(\mathrm{p}=0.03, \mathrm{p}=0.04)$.
Table-II

Clinical profile of the study patients $(n=200)$

\begin{tabular}{lcccc}
\hline Parameters & $\begin{array}{c}\text { Group I } \\
(\mathrm{n}=100)\end{array}$ & $\begin{array}{c}\text { Group II } \\
(\mathrm{n}=100)\end{array}$ & $\mathrm{p}$ value \\
\cline { 2 - 3 } & Mean SD & Mean SD & \\
\hline Pulse/minute & $81.0 \pm 6.9$ & $81.9 \pm 6.2$ & $0.31^{\mathrm{NS}}$ \\
$\begin{array}{l}\text { Systolic blood } \\
\text { pressure (mmHg) }\end{array}$ & $111.6 \pm 10$. & $113.2 \pm 9.4$ & $0.12^{\mathrm{NS}}$ \\
$\begin{array}{l}\text { Diastolic blood } \\
\text { pressure (mmHg) }\end{array}$ & $75.2 \pm 6.7$ & $73.1 \pm 6.7$ & $0.10^{\mathrm{NS}}$ \\
$\begin{array}{l}\text { Pulse pressure } \\
\text { BMI }\left(\mathrm{kg} / \mathrm{m}^{2}\right)\end{array}$ & $35.9 \pm 7.7$ & $41.1 \pm 7.5$ & $0.07^{\mathrm{NS}}$ \\
\hline
\end{tabular}

Table-III

Distribution of the study patients according to vessel score $(n=200)$

\begin{tabular}{lcccccc}
\hline Vessel Score & \multicolumn{2}{c}{$\begin{array}{c}\text { Group I } \\
(\mathrm{n}=100)\end{array}$} & & \multicolumn{2}{c}{$\begin{array}{c}\text { Group II } \\
(\mathrm{n}=100)\end{array}$} & P value \\
\cline { 2 - 3 } \cline { 5 - 6 } & Number & $\%$ & & Number & $\%$ & \\
\hline Score -0 & 14 & 14.0 & & 7 & 7.0 & $0.03^{\mathrm{S}}$ \\
Score -1 & 50 & 50.0 & & 27 & 27.0 & $0.001^{\mathrm{S}}$ \\
Score -2 & 18 & 18.0 & 30 & 30.0 & $0.04^{\mathrm{S}}$ \\
Score -3 & 18 & 18.0 & 36 & 36.0 & $0.004^{\mathrm{S}}$ \\
\hline
\end{tabular}

Table III shows the vessel score of the study patients. It was found that among group II, highest percentage was of 3 vessel score $(36 \%)$ followed by 2 vessel score $30 \%$. Twenty seven percentage patient had 1 vessel score and $7 \%$ had 0 vessel score. On the contrary among group I, highest percentage was of 1 vessel score (50\%).18\% belonged to both 2 and 3 vessel score and $14 \%$ patient had 0 vessel score. 0 and 1 vessel involvement were significantly higher in group I than group II . Two and 3 vessel involvement was also found significantly higher in group II.

Table-IV

Association between PWV and number of vessels involved $(n=200)$

\begin{tabular}{|c|c|c|}
\hline \multirow{2}{*}{$\begin{array}{l}\text { No. of vessel } \\
\text { involved } \\
\end{array}$} & \multicolumn{2}{|c|}{$\mathrm{PWV}(\mathrm{m} / \mathrm{sec})$} \\
\hline & Mean & $\overline{\mathrm{SD}}$ \\
\hline $\begin{array}{l}\text { No vessel involvement } \\
(\mathrm{n}=21)\end{array}$ & 8.10 & 2.90 \\
\hline Single $(n=77)$ & 10.65 & 3.46 \\
\hline Double $(\mathrm{n}=48)$ & 13.85 & 3.80 \\
\hline Triple $(n=54)$ & 15.70 & 4.66 \\
\hline
\end{tabular}

Table IV shows that the mean PWV of subjects with normal angiographic findings was $8.10 \pm 2.9$ $\mathrm{m} / \mathrm{sec}$. The mean PWV of single, double and triple 
vessel disease were $10.65 \pm 3.46,13.85 \pm 3.80$ and $15.70 \pm 4.66(\mathrm{~m} / \mathrm{sec})$ respectively. The PWV increased in proportion with the number of vessel involvement and the differences were statistically significant $(p=0.001)$.

\section{Table-V}

Distribution of the study patients according to Friesinger score $(n=200)$

\begin{tabular}{|c|c|c|c|c|c|}
\hline \multirow[t]{2}{*}{ Friesinger Score } & \multicolumn{2}{|c|}{$\begin{array}{c}\text { Group I } \\
(n=50)\end{array}$} & \multicolumn{2}{|c|}{$\begin{array}{l}\text { Group II } \\
(\mathrm{n}=50)\end{array}$} & \multirow[t]{2}{*}{$\mathrm{P}$ value } \\
\hline & Number & $\%$ & Number & $\%$ & \\
\hline Normal (0) & 14 & 14.0 & 7 & 7.0 & $0.03^{\mathrm{S}}$ \\
\hline Low (1-4) & 43 & 43.0 & 17 & 17.0 & $0.001^{\mathrm{S}}$ \\
\hline Intermediate (5-10) & 27 & 27.0 & 41 & 41.0 & $0.04^{\mathrm{S}}$ \\
\hline High (11-15) & 16 & 16.0 & 35 & 35.0 & $0.002^{\mathrm{S}}$ \\
\hline
\end{tabular}

Above table shows that normal and low Friesinger score were higher and statistically significant in group I $(p=0.03$ and $p=0.001$ respectively). Intermediate and high Friesinger score were significantly higher in group II. $(\mathrm{p}=0.04$ and $\mathrm{p}=0.002$ respectively).

Table-VI

Mean status of $P W V$ of the study patients according to significant coronary artery disease defined by Friesinger index $(n=200)$

\begin{tabular}{|c|c|c|c|}
\hline $\mathrm{PWV} \mathrm{m/sec}$ & $\begin{array}{c}\text { Insignificant CAD } \\
(\mathrm{n}=81) \text { (Friesinger } \\
\text { score 0-4) }\end{array}$ & $\begin{array}{c}\text { Significant CAD } \\
(\mathrm{n}=119)(\text { Friesinger } \\
\text { score } \geq 5)\end{array}$ & $\mathrm{p}$ value \\
\hline Mean & 8.52 .3 & 12.53 .7 & $0.001^{\mathrm{S}}$ \\
\hline
\end{tabular}

Table VI shows the mean value of PWV $(\mathrm{m} / \mathrm{sec})$ was observed 12.53 .7 and 8.52.3 in significant and insignificant CAD respectively. The difference of mean value of PWV between the insignificant and significant $\mathrm{CAD}$ groups was statistically significant $(\mathrm{p}=0.001)$.

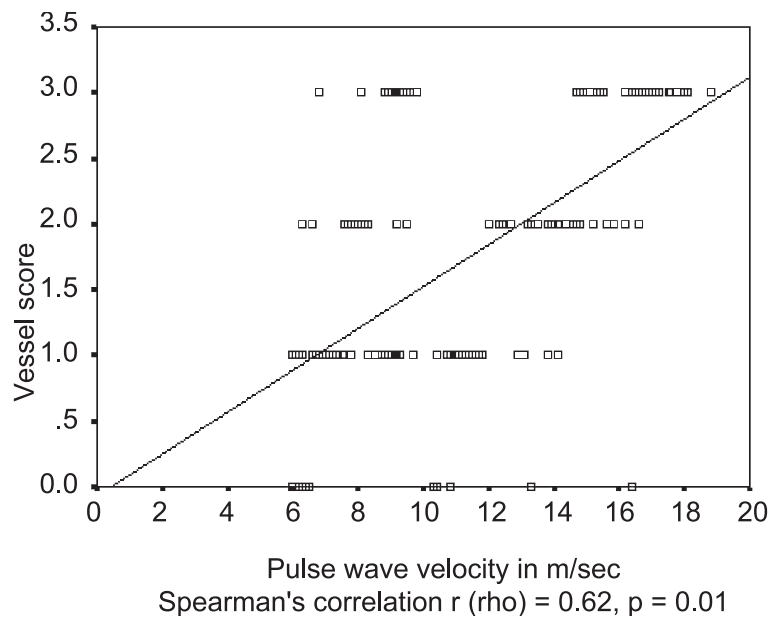

Fig.-1: Correlation between $P W V$ and vessel score

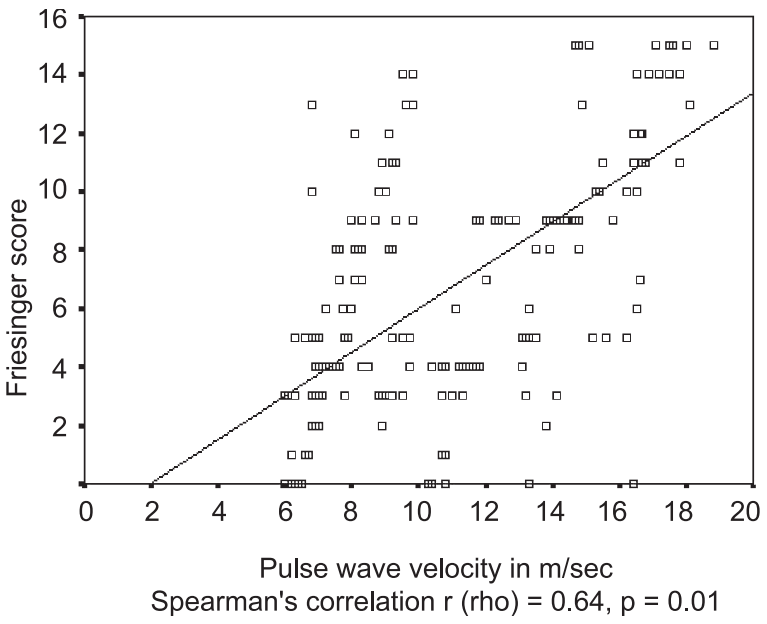

Fig.-2: Correlation between $P W V$ and Friesinger vessel score

Figure 1and 2 shows there was statistically significant $(\mathrm{p}=0.01)$ positive correlation between PWV and CAD severity in terms of vessel score $(\mathrm{r}=0.62)$ and Friesinger score $(\mathrm{r}=0.64)$.

\section{Table-VII}

Multivariate logistic regression analysis of $C A D$ (by Friesinger score) considering as dependent variable.

\begin{tabular}{lcccc}
\hline Variables of interest & $\mathrm{B}$ & $\mathrm{p}$ value & $\mathrm{OR}$ & $95 \% \mathrm{CI}$ \\
\hline Age $>50$ yrs & 0.197 & 0.61 & 1.218 & $0.568-2.611$ \\
Smoking & 0.610 & 0.110 & 0.544 & $0.257-1.150$ \\
Diabetes mellitus & 0.678 & 0.084 & 1.969 & $0.914-4.244$ \\
Hypertension & 1.118 & $0.004 \mathrm{~S}$ & 3.060 & $1.434-6.527$ \\
Dyslipidemia & 0.265 & 0.468 & 1.304 & $0.637-2.669$ \\
PWV & 0.243 & $0.001^{\mathrm{S}}$ & 1.275 & $1.159-1.404$ \\
\hline
\end{tabular}

Dependent variable: CAD;

Independent variables: age > 50 yrs, smoking, diabetes mellitus, hypertension, dyslipidemia and PWV

$\mathrm{S}=$ Significant

Table VII demonstrates the binary logistic regression analysis where among the 6 variables hypertension $(p=0.004)$ and PWV $(p=0.001)$ were found to be the significant independent predictors of severe $\mathrm{CAD}$ with $\mathrm{OR}$ of 3.060 and 1.275 respectively.

\section{Discussion:}

The mean age of group I was $51.2 \pm 9.2$ years ranging from 26 to 62 years and the mean age of group II was $52.4 \pm 9.1$ years ranging from 30 to 62 year. The mean age of group II was higher than group I but the difference between the two groups was not statistically significant $(\mathrm{p}=0.09)$. Alarhabi, et al. ${ }^{14}$ found the mean age of his study 
subjects was $54.1 \pm 9.10$ years which was similar to the present study.

In this study, baseline parameters like age, sex, body mass index, risk factors for $\mathrm{CAD}$, clinical examination findings, baseline biochemical results and left ventricular ejection fraction showed no statistically significant differences among the study subjects of two groups except the incidence of risk factors e.g. smoking and family history of premature $\mathrm{CAD}$, the difference of which was significantly higher in group II.

In this study, it was found that in group I the distribution of patients in terms of vessel score was score 0 (14\%), score 1 (50\%), score $2(18 \%)$, score $3(18 \%)$. Whereas, in group II the distribution of patients in terms of vessel score was score $0(7 \%)$, score $1(27 \%)$, score $2(30 \%)$, score $3(36 \%)$. Vessel score 0 and vessel score 1 were found significantly higher in group I ( $p<.05)$. Vessel score 2 and vessel score 3 were significantly higher in group II $(\mathrm{p}<.05)$.

The mean PWV of subjects with normal angiographic findings was $8.10 \pm 2.9 \mathrm{~m} / \mathrm{sec}$. The mean PWV of single, double and triple vessel disease were $10.65 \pm 3.46,13.85 \pm 3.80$ and $15.70 \pm 4.66(\mathrm{~m} / \mathrm{sec})$ respectively. So the PWV increased in proportion with the number of vessel involved by $\mathrm{CAD}$ and the differences were statistically significant $(\mathrm{p}=0.001)$. The findings of the present study is consistent with those studies conducted by Alarhabi, et al. ${ }^{14}$ Aditya, et al. ${ }^{15}$ and Ouchi, et al. ${ }^{16}$ But the values of PWV differed that of study done by Fukuda, et al. ${ }^{17}$ as because ankle-brachial PWV was measured instead of carotid femoral PWV in the former study.

In the present study, analysis of Friesinger score revealed Friesinger score, normal (0) was found in $14 \%$ and in $7 \%$ patients in group I and II respectively. Friesinger score, low (1-4) was found in $43 \%$ and in $17 \%$ patients in group I and II respectively. Friesinger score, intermediate (5-10) was found in $27 \%$ patients in group I and in $41 \%$ patients in group II. Friesinger score, high (11-15) was found in $16 \%$ patients in group I and $35 \%$ patients in group II respectively. Normal and low Friesinger score were significantly higher in group I $(p=0.03$ and $\mathrm{p}=0.001$ respectively). Intermediate and high
Friesinger score were significantly higher in group II ( $\mathrm{p}=0.04$ and $\mathrm{p}=0.002$ respectively).

Friesinger score 0-4 was defined as insignificant CAD whereas Friesinger score e" 5 was defined as significant CAD. The mean PWV was observed $12.53 .7 \mathrm{~m} / \mathrm{sec}$ and $8.52 .3 \mathrm{~m} / \mathrm{sec}$ in significant and insignificant CAD respectively. The difference of mean value of PWV between the significant and insignificant CAD groups was statistically significant $(p=0.001)$, hence, PWV was significantly higher in patients with significant CAD. Lee, et al. ${ }^{18}$ and Covic,et al. ${ }^{19}$ found that PWV was higher in the significant lesion than in the insignificant lesion as well as, as more coronary vessels were affected, PWV increased proportionately which supports our study findings.

In this study there was a significant $(p=0.01)$ positive correlation between aortic PWV and coronary artery disease severity in terms of vessel score $(r=.62)$, friesinger $\operatorname{score}(r=.64)$ and Leaman score $(r=0.45)$. Hope, et al. ${ }^{20}$ found in his study that the stenosis score were independently associated with aortic PWV $(\mathrm{r}=.58, \mathrm{p}<.001)$ whereas, Lee, et al. ${ }^{18}$ found that the modified stenosis score had a positive correlation with PWV $(\mathrm{r}=.55, \mathrm{p}<. .001)$. These findings are consistent with those of present study.

In the present study, logistic regression analysis revealed that, hypertension $(\mathrm{p}=.004)$ and aortic PWV ( $p=.001)$ were independent predictors of coronary artery disease. Moreover after adjusting age, smoking, diabetes mellitus, hypertension and dyslipidemia, aortic PWV was significantly associated with severe CAD with OR of 1.275. The findings are similar to the studies done by Kullo, et al. ${ }^{21}$ and Laurent, et al. ${ }^{22}$

\section{Conclusion:}

In conclusion, from this study we may state that arterial stiffness, as measured by the aortic pulse wave velocity, is an independent predictor of extent of coronary artery disease. This noninvasive evaluation method may be used as a useful marker of end organ damage in arterial system and help to identify patients at high risk for coronary artery disease. Early screening may 
help in early diagnosis and treatment of underlying vascular conditions before development into more serious illness.

\section{Study limitation:}

Although the result of this study supports the hypothesis, there is some fact to be considered which might affect the result:

- This was a single center study with a relatively small sample size.

- Purposive sampling was done instead of random sampling method.

- Study was conducted only with acute STEMI patients, so our findings may not be applicable to the general population.

- Angiographic severity of coronary artery disease was evaluated by visual estimation, so chance of inter observer and intra observer variation remained.

\section{Conflict of Interest - None.}

\section{References:}

1. Vanhoutte PM. Endothelial control of vasomotor function: From health to coronary artery disease. Circ J 2003; 67: $572-575$.

2. Oliver JJ, Webb DJ. Noninvasive assessment of arterial stiffness and risk of atherosclerotic events. Arterioscler Thromb Vasc Biol 2003; 23: 554-566.

3. Hayashi T, Nakayama Y, Tsumurak M, Yoshimaru K. Reflection in the arterial system and the risk of coronary artery disease. Am J Hypertens 2002; 15: 415-419.

4. Madhavan S, Ooi WL, Cohen H, Alderman MH. Relation of pulse pressure and blood pressure reduction to the incidence of myocardial infarction. Hypertension 1994; 23:395-401.

5. Farro I, Bia D, Yanina Z. Pulse wave velocity as marker of preclinical arterial disease: reference levels in a Uruguayan population considering wave detection algorithms, path lengths, aging, and blood pressure. International Journal of Hypertension 2012; 20:882-892.

6. Oh KJ, Tajik JA, Seward BJ.The Echo Manual. $3^{\text {rd }}$ ed. New Delhi: Lippincott Williams \& Willkins, 2010:383-389.

7. Wang D, Tang Q, Shin SH, Hua Q. Prediction of coronary artery diseases in pulse wave velocity and retinal artery lesions. Tohuko J Exp Med 2011; 225:17-22.

8. Tomiyama H, Koji Y,Yambe M, Shina K, Motobi K, Yamada J.Pulse wave velocity is a simple and independent predictor of prognosis in patients with acute coronary syndrome. Circulation 2005;69:815-822.
9. Elias MF, Dore GA, Davey A, Abhayaratna WA. Norms and reference values for pulse wave velocity: one size does not fit all. J Biosci Med 2011;1:2.

10. Ringqvist I, Fisher LD, Mock M, Devis KB. Prognostic value of angiographic indices of coronary artery disease from the Coronary Artery Surgery Study (CASS). J Clin Invest 1983; 71:1854-1866.

11. Chaitman BR, Bourassa MG, Davis K. Angiographic prevalence of high risk coronary artery disease in patients subsets. Circulation 1981; 64: 360-367.

12. Sullivan DR, Thomas H, Marwick S, Ben FD. A new method of scoring coronary angiograms to reflect extent of coronary atherosclerosis and improve correlation with major risk factors. Am Heart J 1990; 119:1262-1267.

13. Leaman DM, Brower RW, Meester GT. Coronary artery atherosclerosis: severity of the disease, severity of angina pectoris and compromised left ventricular function. Circulation 1981; 63: 285-299.

14. Alarhabi AY, Mohamed S, Ibrahim S, Hun TM. Pulse wave velocity as a marker of severity of coronary artery disease. J Clin Hypertens 2009;11: 17-21.

15. Aditya MS, Balamani G, Rames P, Kumar S. Measurement of pulse wave velocity in patient of $\mathrm{CAD}$ and correlation with disease severity in coronary angiogram. Indian Heart Journal 2007; 22: 34-36.

16. Ouchi Y, Terashita K, Nakamura T, et al. Aortic pulse wave velocity in patients with coronary atherosclerosis-a comparison with coronary angiographic findings. Nihon Ronen Igakkai Zsshi 1999; 28: 40-45.

17. Fukuda D, Yoshiyama M, Shimada K. 2006. Relation between aortic stiffness and coronary flow reserve in patients with coronary artery disease. Heart 2006; 92 : 759-762.

18. Lee SY, Kim KS, Wang R, Nam CW. Clinical implication of carotid-radial pulse wave velocity for patients with coronary artery disease. Korean Circ J 2006; 36: 565-572.

19. Covic A, Haydar AA, Bhamra-ariza P, Gusbeth-tatomir $\mathrm{P}$, Goldsmith DJ. Aortic pulse wave velocity and arterial wave reflections predict the extent and severity of coronary artery disease in chronic kidney disease. J Nephrol 2005; 18: 388-396.

20. Hope SA, Antonis P, Adam D, Camerron JD, Meredith IT. Arterial pulse wave velocity but not the augmentation index is associated with coronary artery disease extent and severity: implication for arterial transfer function applicability. J Hypertens 2007; 25: 2105-2109.

21. Kullo JI, Bielak LF, Turner ST, Peyser PA. Aortic pulse wave velocity is associated with the presence and quantity of coronary artery calcium. Hypertension 2006; 47: 174-179.

22. Laurent S, Boutouyrie P, Manua H, Asmar R. Aortic stiffness is an independent predictor of all cause and cardiovascular mortality in hypertensive patients. Hypertension 2001; 37: 1236-1241. 